\title{
The Effect of CPR Workshop on the Nurses' Level of Knowledge and Skill \\ ORIGINAL
}

\section{Abstract}

Background \& Aim: The significance of cardiopulmonary resuscitation (CPR) used by nurses in their professional success has been discussed. The aim of this study is to determine the effect of workshop training method on the nurses' knowledge and skill of CPR.

Material \& Methods: This quasi-experimental study was conducted on 140 nurses of Zabol University of Medical Science in a single group (before and after and three months after the training workshop) .The data collection tool was the knowledge questionnaire including personal information and 50 questions which were designed based on valid sources. To assess the nurses' practical skills, a checklist was used by observing CPR performance on the manikin (manikin CPR performance). The tools were completed for all the nurses before and after the training workshop and three months later. After their collection, the data were converted to digital codes and entered SPSS computer software and were analyzed based on descriptive and inferential statistics.

Results: The average score of nurses' level of knowledge and skill after educational intervention had a significant difference with the average score of their level of knowledge and skill before training $(p<0.05)$.

Conclusion: Workshop training method on CPR can be useful and effective in the nurses' knowledge and skill.
Aziz Shahrakivahed, MScN, Faculty Member, Zabol University of Medical Sciences, Zabol, IR Iran. Email: azizshahraki@zbmu.ac.ir

Nosratolah Masinaienezhad, MScN, Faculty Member, Zabol University of Medical Sciences, Zabol, IR Iran.

Hossien Shahdadi, MScN, Faculty Member, Zabol University of Medical Sciences, Zabol, IR Iran.

\section{Azizollah Arbabisarjou}

(Corresponding Author), Pregnancy Health Research Center, Zahedan University of Medical Sciences, Zabol, IR Iran. Email: derranneh2005@yahoo.com

Elaheh Asadibidmeshki, MSc in Psychiatric Nursing, Faculty Member, Zabol University of Medical Sciences, Zabol, IR Iran.

Maryam Heydari, MScN in Anesthesiology, Faculty member, Zabol University of Medical Sciences, Zabol, IR Iran.

\section{Keywords}

Training, Knowledge, Skill, Nurse, Cardiopulmonary Resuscitation (CPR) 


\section{Introduction}

Cardiac arrest occurs in case of cessation of effective heartbeat and blood circulation (1) and it is one of the causes of sudden or unexpected death which may occur at any time or place (2). Cardiopulmonary resuscitation (CPR) operation, as a basic skill, is one of the most important inventions of the history of medicine and a rapid and urgent intervention to prevent death or postpone it in a patient with cardiac arrest (3).

Various levels of CPR include: Basic life support measures which are conducted for opening the airway and oxygenation and maintaining blood circulation at the primary level, advanced resuscitation measures that are done for maintaining blood circulation and oxygenation at the advanced level and long-term resuscitation measures that are done for brain or cerebral resuscitation and improvement of the brain tissue and stabilization of the patient (4).

CPR operations are carried out by trained, skillful, knowledgeable and active persons and encountering such an issue must be scientifically and practically qualified based on scientific principles, legal standards and human resources (5).

The data have shown that adverse outcomes of most CPRs have been a result of selection of inappropriate or ineffective methods and the final results of CPR depend on precision in the details of resuscitation methods which are mostly ignored but most people know the general facts about them (6). Nurses are among the first members of the treatment team that are present in the early stages of CPR operations. Thus, one of the few issues that is greatly emphasized in training of the nurses is CPR operation training. As stated by Kuckler et al., in the nursing education program the principles of the CPR method must be taught to the nurses so that they will be able to intervene in the operations in the best way they can $(5,7)$.

In 1996, CPR training became obligatory for the health personnel in the U.S. and by 1987, 12000000 people were trained in the introductory and advanced courses of CPR (8). Despite the new techniques in development of knowledge and awareness, lecture is one of the important training methods and is a useful method for group training (9). Hamilton in a 20-year review investigated the effect of various training methods on the nurses' sustained learning of knowledge and skill and in his conclusion introduced the best methods by means of computer program training and voiced manikins and computer simulation (10). CPR training not only assures the nurses about acquiring knowledge and skill on CPR, but also leads to their knowledge and skill retention for successful CPR (11). Since the late 1980s, several studies have been conducted on skill in CPR. Some of these studies showed the effect of presence of trained people on the outcome of resuscitation, in such a way that the results of one of these studies indicated that even the presence of one person with more skills can have a considerable effect on the outcome of resuscitation.

Education researchers believe that every education or training leads to learning but the depth and stability of learning differs in various training methods. A large part of studies in recent years has investigated the effectiveness of various training programs in the field of creating sustainable learning (12). Monjamed et al. (2005), in their study, showed that most (6.56\%) of the students and $3.64 \%$ had achieved the highest level of awareness of basic CPR in the lecture and manikin method and in the lecture and film method respectively (9).

Adib Hajbagheri (1998), in his study entitled "investigation of knowledge and skill of the medical personnel of Kashan hospitals in the field of CPR resuscitation", showed that none of the research units had good knowledge on CPR and $82 \%$ of them had low knowledge and also 71\% of the research units had low skills (13). Cardiopulmonary arrest is undoubtedly one of the most critical conditions that requires urgent and careful action so as to protect life and avoid irreparable damages to 
the vital body systems. As CPR is conducted based on special protocols and the pre-requirement for its implementation is the reviver's acquisition of underlying knowledge, skill and experience, the step by step training of CPR operation by trained nurses is therefore quite necessary and the present stu$d y$ is aimed at assessing the effect of CPR training workshop on the level of knowledge and skill of the nurses working in hospitals.

\section{Method}

This research was a quasi-experimental study as group trial with pre-test and post-test plan by implementing treatment workshop on 140 nurses working in the hospitals affiliated to Zabol University of Medical Science and with the collaboration of the respectable officials of the School of Nursing and Midwifery in 2010. After coordination with the nursing managers and training supervisors of affiliated hospitals and the call for holding workshops and registration of people in the CPR training workshop, during 21 days from 8 a.m. to 2 p.m. groups of 20 were formed and each group underwent 18 hours of training during three days ( 6 hours of theory and 6 hours of practice, 6 hours of review and test) in the School of Nursing and Midwifery. In the theoretical training, the following were practiced and repeated: epidemiology, the definition of sudden cardiac arrest, basic and advanced resuscitation measures among adults, children and infants, the principles of application of defibrillator (electroshock or ECT), diagnosis principles of arrhythmias and their treatment, injection and medical attentions before, during and after cardiac arrest, postresuscitation complications and care (for 6 hours) and in the practical trainings on Laerdal Company resuscitation manikin (of Norway) and after the provision of equipment for ventilation, tracheal tube, laryngoscopy in Clinical Skills Lab of the Faculty by the professors, skills in heart massage, laryngosco- py, tracheal intubation, fixing and assurance of its application on the manikin were also practiced and repeated. Also, the principles and application of ECT device were explained and on the third day, the nurses' skills were tested.

To hold the training workshop, the faculty members of the University of Medical Science who were familiar with the teaching process and had up-todate knowledge of CPR were used. The workshop was held by means of video projector slide show. The content of the workshop was based on the 2010 Guide to America Heart Association (AHA) (14) and was held in four sections including: opening the airway and maintaining respiration, maintaining the blood circulation, drugs and defibrillator and post-CPR care.

The data collection tool was the knowledge assessment questionnaire of the participating nurses which was regulated in two parts; the first part included personal specifications and the second part was comprised of 50 multiple choice questions on the required measures in basic and advanced CPR operations among the adults, children and infants. From among these, 5 questions were on identification of cardiac arrest and the starting of CPR, 7 questions on opening the airway, 3 questions on maintaining the blood circulation, 9 questions on heart massage, 8 questions on identification of cardiac arrhythmia, five questions on drug injection, 3 questions on the use of defibrillator, 6 questions on intubation and 4 questions on the post-resuscitation complications and care. To determine the knowledge level of the research units, the correct answer was scored 1 and the wrong answer was scored 0. Thus, the maximum score was 50 and the minimum score was 0 . The knowledge score at the three levels of good, average and low were considered with the score ranges of 33-50, 17-32 and 0-16.

To investigate the reliability of the tools, as for the questions on knowledge similar studies (such as researcher-made questionnaire by Ms. Mokhtari) were used, its reliability with the coefficient of $83 \%$ 
was confirmed.

Before the starting of the workshop, in order to determine the knowledge of the nurses attending the workshop, the developed questionnaires were given to them and were collected after 25 minutes. At the end of the workshop, the questionnaire was given to the participants once more and were collected after 25 minutes and a pamphlet for CPR training was also given to them. None of the participants were informed of the test for the three months later. After three months, in coordination with the managers and training supervisors and by referring to the location of the participants in the study at a proper time in the hospital conference hall, the 50-item questionnaire was given to them again with slight changes (relocation of the questions and options) and without any changes in the level of difficulty and were then collected after 25 minutes.

Checklist of CPR skills of adults and children consisted of 11 steps, checklist of CPR skills of infants consisted of 10 steps, checklist of intubation skills consisted of 7 steps and checklist of CPR skills with the defibrillator device consisted of 10 steps, and each step was determined, based on the nurses' performance on the CPR manikin, by the scores 1 to 4 (excellent, good, average, bad).

The score range of skills was considered as 38152 and the skill levels of the samples, as excellent, good, average and bad, were determined within the score ranges of $125-152,96-124,67-95,38-66$ respectively. Furthermore, the practical skills of the nurses in the hospital were assessed based on the checklist by two researchers (training supervisors or supervisors participating in the workshop in turns) without people's awareness during CPR operations.

Practical skills of the nurses were determined based on the checklist of the skills of CPR of adults, children and infants and from the standard tools of America Heart Association (AHA) (2010). The level of skill of the participants was determined as excellent, good, average and bad according to the error rate during the resuscitation operations and by means of observation checklist. At the end of the training workshop, the participants evaluated the workshop by completing the survey. The scale used was Likert scale ranging from very good (equivalent to the numerical value 4) to bad (equivalent to the numerical value 1).

The data obtained from the three stages before, after and three months after the end of the training workshop were converted to digital codes and entered the SPSS computer software and were analyzed in terms of descriptive statistics (frequency, mean and standard deviation) and inferential statistics.

\section{Research Findings}

The results showed that of 140 participants in CPR training workshop, most people $(5.78 \%)$ were women and $46 \%$ were between the ages of 26 and $30,73 \%$ were married, $70 \%$ had work experience of more than 10 years, $52 \%$ of the samples were on single shift, $46 \%$ of the participants had morning fixed work shift, $43 \%$ were on contract in terms of the employment type, $28 \%$ were working in emergency and the lowest percent was 2\% in Department of Psychiatry and $15 \%$ of the total participants had work experience in ICU.

The given results also showed that the lowest score of knowledge was 12 with the mean of 21 and standard deviation of 85.9. The mean of scores was 21 before training, 41 after training and 5.45 three months after training and with paired t-test significant difference $(P=0.001)$ was observed between the scores of knowledge in the three tests.

These results were 47 and 35 respectively with the mean of 41 and standard deviation of 25.12 for the test after the workshop and they were 48 and 42 respectively with the mean of 5.45 and standard deviation of 36.14 for the test with 3-month delay, in such a way that the results of repeated measurement test showed a significant difference between the mean of 
Table 1. Frequency distribution of the people under study in terms of the score before and after training

\begin{tabular}{|c|c|c|c|}
\hline Score & $\begin{array}{c}\text { Before } \\
\text { training }\end{array}$ & $\begin{array}{c}\text { After } \\
\text { training }\end{array}$ & $\begin{array}{c}\text { Delay test } \\
\text { after three } \\
\text { months }\end{array}$ \\
\hline Highest score & 35 & 47 & 48 \\
\hline Lowest score & 12 & 35 & 42 \\
\hline
\end{tabular}

Table 2. The mean and standard deviation of the knowledge test scores before and after training and re-test (three months after the training workshop)

\begin{tabular}{|l|c|c|c|}
\hline \multicolumn{1}{|c|}{ Score } & $\begin{array}{c}\text { Number of } \\
\text { samples }\end{array}$ & Mean & SD \\
\hline $\begin{array}{l}\text { Pre-test } \\
\begin{array}{l}\text { Immediately after the } \\
\text { training workshop }\end{array}\end{array}$ & 140 & 21 & 5.58 \\
\hline $\begin{array}{l}\text { Three months after the } \\
\text { training workshop }\end{array}$ & 140 & 41 & 12.25 \\
\hline
\end{tabular}

scores of the pre-test and the test after the workshop and the delay test $(\mathrm{P}=0.004)$ (Tables 1, 2, 3).

In the true and false answers of the test before training, the highest level of lack of knowledge of the nurses was in the field of the principles of application of the tracheal tube, diagnosis principles of arrhythmias and their treatment and drug injection and medical attentions. Also, there was low knowledge before training in some issues such as initial efforts to deal with the patient with cardiac arrest, the maneuvers for opening the airway and the proper way of health massage.

The statistical tests didn't show any differences between the mean of scores of knowledge and gender ( $P$-value $<0.05)$. The statistical paired t-test or $\mathrm{P}=0.001$ showed a significant difference between the skills of men and women before and after training.

The statistical test showed a significant difference between the participants in the morning shift and the others in the afternoon and night shifts in terms of the level of knowledge and skill in the field of CPR. Also, none of the units under study with the

Table 3. The mean of scores of the participants' questions before, after and three months after the training

\begin{tabular}{|c|c|c|c|c|c|c|}
\hline \multirow{2}{*}{ Questions } & \multicolumn{2}{|c|}{ Before } & \multicolumn{2}{|c|}{ After } & \multicolumn{2}{|c|}{3 months later } \\
\hline & Mean & SD & Mean & SD & Mean & SD \\
\hline Epidemiology and definition of cardiac arrest & 48 & 10.25 & 50 & 9.85 & 50 & 11.25 \\
\hline Opening the airway (adults, children, infants) & 29 & 8.63 & 43 & 10.26 & 43 & 12.93 \\
\hline $\begin{array}{l}\text { Maintaining the blood circulation (adults, children, } \\
\text { infants) }\end{array}$ & 32 & 9.41 & 48 & 12.58 & 49 & 11.96 \\
\hline $\begin{array}{l}\text { The principles of application of defibrillator device in } \\
\text { adults }\end{array}$ & 21 & 7.97 & 47 & 11.36 & 48 & 11.59 \\
\hline $\begin{array}{l}\text { Diagnosis principles of arrhythmias and their } \\
\text { treatment }\end{array}$ & 14 & 6.31 & 43 & 11.37 & 43 & 13.54 \\
\hline Drug injection and their medical attentions & 16 & 8.56 & 45 & 10.36 & 43 & 12.14 \\
\hline Post-resuscitation complications and care & 17 & 9.65 & 50 & 12.87 & 49 & 13.48 \\
\hline $\begin{array}{l}\text { The principles of application of tracheal tube (adults, } \\
\text { children, infants) }\end{array}$ & 13 & 4.81 & 44 & 10.26 & 42 & 12.52 \\
\hline
\end{tabular}


work experience of 5 years and less had good skills before training.

The statistical test didn't show a significant difference in the score of knowledge acquisition in the participants in terms of the employment type. The Scheffe test with the confidence interval of $95 \%$ among the participants didn't show a significant relationship with the level of knowledge in terms of the variable of work experience and going through previous courses, but it showed a significant relationship with the variable of skill. Also, Scheffe test with the confidence interval of 95\% among the participants showed a significant relationship with the level of knowledge and skill in the field of CPR in terms of working place (emergency, ICU).

No significant difference was observed with the paired t-test between the average level of knowledge and skill in the three tests by participation in CPR workshops.

The level of skills of nurses based on the checklist of America Heart Association (AHA) before and after training showed that the highest defect before training concerned assessment of patient response, delay in opening the airway, imbalance in the number of heart massages and respiration in two-person or double CPR at the right time and insufficient depth pressure, unsuitable angle of hands, delay in selecting the number of tracheal tube and its placement and pressure with insufficient depth when using electroshock (ECT) pads (Table 4). The results also showed that the level of skill of most of the units under study before training was 50\% average and after training $43 \%$ excellent and $36 \%$ good, and this difference was statistically significant. The results also showed that $85 \%$ of the participants were very well satisfied with the CPR training workshop.

\section{Discussion}

In the present study it was shown that there was a significant difference between the mean of sco- res of the pre-test and the test after the workshop and the delay test $(\mathrm{P}<0.001)$ and also in the true and false answers of the test before training, the highest defect was related to patient response assessment, delay in opening the airway, imbalance in the number of heart massages and respiration in two-person or double CPR at the right time and insufficient depth pressure, unsuitable angle of the hands, delay in selecting the number of tracheal tube and its placement and pressure with insufficient depth when using electroshock (ECT) pads. Barimnejad et al. also showed in their study that in the comparison of the mean of the results of the three tests there was a significant difference between the mean of scores of the pre-test and the test immediately after the workshop and the delay test. They also showed that in the information on pre-test scores, the highest defect of the participants was related to the lack of knowledge on electroshock (ECT) and rhythm identification, which are in line with the results of the study (12).

In the study by Bakhsha et al. entitled "the effect of CPR training on the knowledge of the nurses working in health centers affiliated to Golestan Province University of Medical Science", the findings showed that knowledge of common arrhythmias caused death and current therapeutic protocols before training were very low and were not so suitable concerning medication, which confirm the results of the present study before the training of the participants. Also, in Bakhsha's research results, it was shown that after training, the level of knowledge increased considerably. However, in some issues such as cardiac arrest, initial efforts in dealing with the patient with cardiopulmonary arrest, the maneuver for opening the airway and the method of doing massages, the knowledge was not considerable. In the present study also, the level of knowledge was higher after the workshop (15). In the present study, the mean of scores was 21 before training, 41 after training and 5.45 three months after training, and with t-test a significant difference $(P=0.001)$ was 
Table 4. Study of the level of skills of nurses based on the checklist of America Heart Association (AHA) (2005) before and after the training

\begin{tabular}{|c|c|c|c|c|c|c|c|c|c|}
\hline \multirow{2}{*}{ Assessment field } & \multirow{2}{*}{$\begin{array}{c}\text { The } \\
\text { number of } \\
\text { Samples }\end{array}$} & \multicolumn{2}{|c|}{ Excellent } & \multicolumn{2}{|c|}{ Good } & \multicolumn{2}{|c|}{ Average } & \multicolumn{2}{|c|}{ Bad } \\
\hline & & Before & After & Before & After & Before & After & Before & After \\
\hline $\begin{array}{l}\text { Patient response } \\
\text { assessment (adults, } \\
\text { children) }\end{array}$ & 140 & 30 & 138 & 30 & 2 & 50 & - & 30 & - \\
\hline $\begin{array}{l}\text { Reponses assessment in } \\
\text { infants }\end{array}$ & 140 & 20 & 120 & 40 & - & 60 & - & 20 & - \\
\hline $\begin{array}{l}\text { The method of artificial } \\
\text { respiration by mask and } \\
\text { the accuracy of conducting } \\
\text { ventilation }\end{array}$ & 140 & 25 & 80 & 30 & 35 & 50 & 5 & 35 & - \\
\hline $\begin{array}{l}\text { Checking the pulse in } \\
\text { adults and children }\end{array}$ & 140 & 80 & 140 & 30 & - & 10 & - & - & - \\
\hline $\begin{array}{l}\text { Checking the pulse in } \\
\text { infants }\end{array}$ & 140 & 60 & 138 & 25 & 2 & 35 & - & - & - \\
\hline $\begin{array}{l}\text { The principles of doing } \\
\text { heart massage in adults }\end{array}$ & 140 & 35 & 120 & 30 & 20 & 60 & - & 15 & - \\
\hline $\begin{array}{l}\text { The principles of doing } \\
\text { heart massage in children }\end{array}$ & 140 & 40 & 130 & 30 & 10 & 50 & - & 20 & - \\
\hline $\begin{array}{l}\text { The principles of doing } \\
\text { heart massage in infants }\end{array}$ & 140 & 20 & 122 & 30 & 10 & 40 & 8 & 50 & - \\
\hline $\begin{array}{l}\text { The principles of } \\
\text { application of electroshock } \\
\text { or ECT (turning on, alert } \\
\text { warning, type of pad, } \\
\text { pressure with sufficient } \\
\text { depth) }\end{array}$ & 140 & 40 & 130 & 45 & 10 & 40 & - & 15 & - \\
\hline $\begin{array}{l}\text { Principles of intubation } \\
\text { (number of tracheal tube, } \\
\text { insertion of tube, fixing and } \\
\text { assurance of placement) }\end{array}$ & 140 & 25 & 110 & 30 & 20 & 20 & 10 & 65 & - \\
\hline $\begin{array}{l}\text { Preparing laryngoscope } \\
\text { and its application (how to } \\
\text { handle it, the type of blade } \\
\text { used, etc.) }\end{array}$ & 140 & 60 & 135 & 50 & 5 & 30 & - & - & - \\
\hline Two-person or double CPR & 140 & 40 & 115 & 30 & 30 & 40 & 5 & 30 & - \\
\hline
\end{tabular}


observed between the scores of knowledge in the three tests. Mokhtari et al., in their study entitled "investigation of the effect of basic CPR course retraining on the level of knowledge and skill of the nurses", showed that the mean and standard deviation of the scores of knowledge in the pre-test and post-test and the delay test were calculated with paired t-test, and the mean of scores was 95.10 before training, 96.17 immediately after training and 12.16 ten weeks after training and with $P=0$, a significant difference was observed between the scores of the three stages, which confirms the present study (11). In this study, a significant relationship was observed with the level of knowledge and skill in the field of CPR in terms of service location (emergency, ICU) and in the study by Mokhtari et al., the score mean of special awareness at work and non-special awareness at work in the test immediately after training was obtained as 33.18 and 56.18 and with paired t-test a significant difference was observed, which confirms the present study.

Holding CPR training workshops in training individuals leads to the effectiveness of the quality of CPR and is the major cause of the possible success of CPR operation (16).

Furthermore, in the study by Mokhtari et al., statistical tests did not show a difference between the mean of scores of knowledge and gender and showed a significant difference between the mean of scores of skill of men and women before training. In the present study, statistical tests did not show any differences between the mean of scores of knowledge and gender but showed a significant difference between the skill of men and women before and after training (11).

Greig et al. (1996) in their studies showed that the highest numbers of personnel were competent in CPR skill and the different levels of competence varied from 0 to $100 \%$ and the score of CPR skill and doing heart compression was ranked the lowest (17). The studies by Davies, Pottle and Brant (2000) also showed that nurses' performance in CPR was poor $(18,19)$. The present study also showed that before training, nurses had a poor performance in CPR (poor performance before training related to assessment of patient response, delay in opening the airway, imbalance in the number of heart massages and respiration in two-person or double CPR at the right time and insufficient depth pressure, unsuitable angle of hands, delay in selecting the number of tracheal tube and its placement and pressure with insufficient depth when using electroshock (ECT) pads.)

In this study, the mean of score of knowledge and skill of the nurses after the training intervention had a significant difference with the mean of score of their knowledge and skills before training $(P<0.05)$. Davies and Madden (2006) proved the effect of re-training on CPR ability in their study $(17,19)$. Also, in the study by Mokhtari Nuri et al., the level of knowledge and skill of nurses increased following the CPR training program (11).

The results of the study by Barimnejad et al. (2003) in this regard indicated the necessity of retraining and updating of knowledge and awareness and upgrading of the level of skill of the health care staff and forming of the expert CPR team in the training planning of hospitals (12). Adib Hajbagheri in his study showed that none of the research units in CPR had good level of knowledge and $82 \%$ of them had low knowledge. Also, 71\% of the research units had low skill and $7.5 \%$ of them had good level of skills (13). In the present study, it was also shown that the level of skill of most of the units 
under study before training was 50\% average and after training $43 \%$ excellent and $36 \%$ good.

\section{Conclusion}

Low level of knowledge and skill of the nurses on CPR, the effect of training on promotion of knowledge and skill of the nurses and the necessity of holding regular and continuous courses CPR for stabilization and necessity of holding were the important findings of this study. This study is a strong proof for supporting the vital role of CPR training in promoting the competency and successful operations in CPR, specifically in cardiopulmonary emergency events.

\section{Acknowledgment}

We hereby thank the Education and Research Deputy of Zabol University of Medical Science that has afforded the costs of this project. We also acknowledge the great efforts of the supervisors of the hospitals and all the personnel participating in the study, without whose participation this study would not have been carried out.

\section{References}

1. Brunner and Suddarths Textbook of Medical-Surgical Nursing cardiac arrest. 12th ed. 2010; Pages 207.

2. Sarah Ringold, Tiffany J Glass, Richard M Glass. Cardiopulmonary resuscitation (CPR). JAMA. 2005; 293(3):388-388.

3. Kokro S, Velasquez E. Predictive indices of survival in patients undergoing cardiopulmonary resuscitation. Atlanta: American College of Chest Physicians; 1999
4. Nikravan mofrad $M$, Gholshani gholbaghi $G H$, Shiri $H$. cardio pulmonary resuscitation in adults. Noordanesh publication 1387; p: 3-4.

5. Alton R. Arrhythmias associated with cardiopulmonary arrest. Nurse Times. 1994;90(19):42-4.

6. Moosavi M. The Principles and Practice of Cardiopulmonary Resuscitation. Jameenegr publication 1383

7. Kuckler S, Kathleen,Klay A, Rese E.CPR in small community. Nursing Management.1987; 18(4).

8. Narouie S, Hashemzehi H, Khani V. cardio pulmonary resuscitation in adults. Abnoos publication.1386; p: 16.

9. Monjamed Z, Haji A, Babaei Gh.R, Beyami A.effect of two teaching methods of CPR (manikin and film), on knowledge and performance of freshman nursing students: A comparative study. IJNR 2006, 1(2): 7-14.

10. Hamilton R. Nurses' knowledge and skill retention following cardiopulmonary resuscitation training: a review of the literAuutre. J Adv Nurs 2005 Aug; 51(3): 288-97.

11. Mokhtari J, Khadem-ol-Hosseini SM, Karimi Zarchi AA, Naimabadi T, Saghafinia M. Survey of Nurses' Acquire and Retain CPR Cognitive Knowledge and Psychomotor Skills Following CPR Trainin. Kowsar Medical Journal 2007; 3(12): 263-271.

12. Barimnejad L., Rasouli M., Barimnejad V., Samiee S., Frequency of Some of the Factors Affecting Adults Cardio -Pulmonary Resuscitation Outcome in Emam Khomeini Hospital, Journal of Rafsenjan University of Medical Sciences, 2005; 4 (4) : 228-235

13. Adib Hajbagheri Mohsen, Afazel Mohamamd Reza, Mousavi Sayed gholam Abbas, Noorizad Samad, Evaluation of knowledge and skills of medical personnels of Kashan hospitals regarding cardiopulmonary resuscitation, KAUMS Journal ( FEYZ ), 2001; 5 (3) : 96-103.

14. Berg RA, Hemphill R, Abella BS, et al. "Part 5: Adult Basic Life Support", 2010 American Heart Association Guidelines for Cardiopulmonary Resuscitation and Emergency Cardiovascular Care. Circulation 2010; 122: S685- 705.

15. Bakhsha F, Behnampour $N$, The effect of CPR training on knowledge of nurses working in the hospitals affiliated to Golestan University of Medical Sciences, Journal of Gorgan University of Medical Sciences, 2007; 8 (4) :46-49.

16. Abella BS, Alvarado JP, Myklebust $H$, et al. Quality of cardiopulmonary resuscitation during in-hospital cardiac arrest. JAMA. 2005; 293: 305-10.

17. Greig M, Elliott D, Parboteeah S, Wilks L. Basic life support skill acquisition and retention in student nurses undertaking a pre- 
registration diploma in higher education/nursing course, Nurse Educ Today. 1996; 16(1): 28-31.

18. Davies N, Gould D, Updating cardiopulmonary resuscitation skills: a study to examine the efficacy of self-instruction on nurses' competence, J Clin Nurs 2000; 9(3): 400-10.

19. Pottle $A$, Brant $S$, Does resuscitation training affect outcome from cardiac arrest?, Accid Emerg Nurs 2000; Jan 8(1): 46-51

\section{Comment on this article:}

\section{(f) $[$ in $8+\mathbf{S} P$}

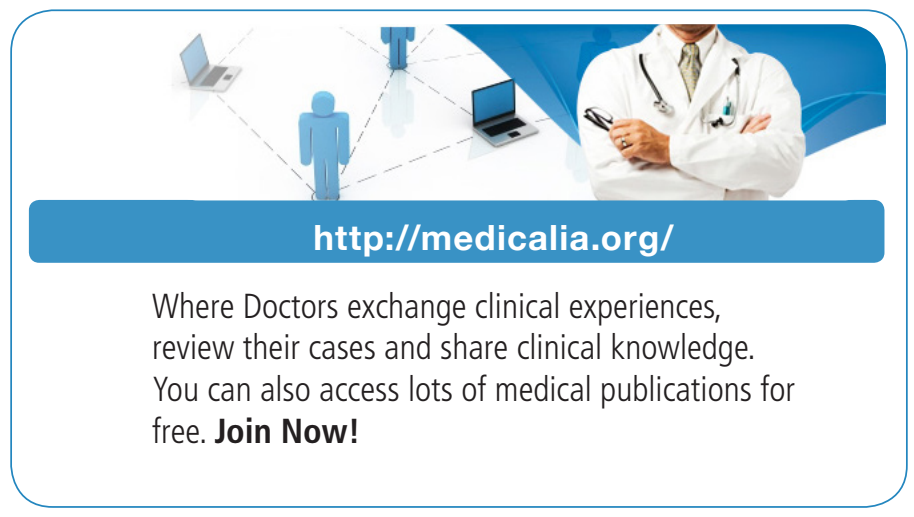

\section{Publish with iMedPub}

\section{http://www.imed.pub}

International Archives of Medicine is an open access journal publishing articles encompassing all aspects of medical science and clinical practice. IAM is considered a megajournal with independent sections on all areas of medicine. IAM is a really international journal with authors and board members from all around the world. The journal is widely indexed and classified Q1 in category Medicine. 